GA-A24493

\title{
GYROTRON POWER BALANCE BASED ON CALORIMETRIC MEASUREMENTS IN THE DIII-D ECH SYSTEM
}

\author{
by \\ I.A. GORELOV, J.M. LOHR, F.W. BAITY, JR., \\ P. CAHALAN, R.W. CALLIS, D. PONCE, and H.K. CHIU
}

MARCH 2004 


\section{DISCLAIMER}

This report was prepared as an account of work sponsored by an agency of the United States Government. Neither the United States Government nor any agency thereof, nor any of their employees, makes any warranty, express or implied, or assumes any legal liability or responsibility for the accuracy, completeness, or usefulness of any information, apparatus, product, or process disclosed, or represents that its use would not infringe privately owned rights. Reference herein to any specific commercial product, process, or service by trade name, trademark, manufacturer, or otherwise, does not necessarily constitute or imply its endorsement, recommendation, or favoring by the United States Government or any agency thereof. The views and opinions of authors expressed herein do not necessarily state or reflect those of the United States Government or any agency thereof. 


\title{
GYROTRON POWER BALANCE BASED ON CALORIMETRIC MEASUREMENTS IN THE DIII-D ECH SYSTEM
}

\author{
by \\ I.A. GORELOV, J.M. LOHR, F.W. BAITY, JR., $\dagger$ \\ P. CAHALAN, $\$$ R.W. CALLIS, D. PONCE, and H.K. CHIU \\ tOak Ridge National Laboratory \\ $\ddagger$ Communications and Power Industries
}

This is a preprint of a paper presented at the 20th IEEE/NPSS Symposium on Fusion Engineering, San Diego, California, October 14-17, 2003 and to be published in Fusion Science and Technology.

\author{
Work supported by \\ the U.S. Department of Energy \\ under Contract Nos. DE-AC03-99ER54463 \\ and DE-AC03-000R22275
}

GENERAL ATOMICS PROJECT 30033

MARCH 2004 


\title{
Gyrotron Power Balance Based on Calorimetric Measurements in the DIII-D ECH System
}

\author{
I.A. Gorelov, J.M. Lohr, F.W. Baity, Jr., P. Cahalan, $\ddagger$ R.W. Callis, D. Ponce, and H.K. Chiu \\ General Atomics, P.O. Box 85608, San Diego, California 92186-5608 \\ $\dagger$ Oak Ridge National Laboratory, P.O. Box 2008, Oak Ridge, Tennessee 37831 \\ $\uparrow$ Communications and Power Industries, 811 Hansen Way, Palo Alto, California 94304
}

\begin{abstract}
A powerful microwave system operating at the second harmonic of the electron cyclotron frequency on the DIII-D tokamak was upgraded up to six assemblies of $110 \mathrm{GHz}$ gyrotrons in 2003. Three Gycom gyrotrons nominally generate $750 \mathrm{~kW}$ for $2 \mathrm{~s}$ pulses, with the pulse length limit resulting from the peak temperature allowed on the boron nitride $\mathrm{rf}$ output window. Three Communications and Power Industries (CPI) gyrotrons with diamond windows have been recently installed and have been tested to 0.9-1.0 MW for $5 \mathrm{~s}$ pulses. Heat loading on internal parts of the gyrotrons, the matching optics unit and the dummy loads is measured calorimetrically. This paper discusses the calorimetry system and calorimetric measurements of gyrotron performance.
\end{abstract}

\section{INTRODUCTION}

The primary purpose of the gyrotron calorimetry system on DIII-D is to estimate the rf power radiated into the tokamak vacuum vessel. This requires measurement of the water flow through the cooling circuits and the initial and final water temperatures in each cooled circuit. The generated power is determined from the sum of the power loading of the gyrotron output window and the $\mathrm{rf}$ beam handling and coupling components plus the dummy loads. In addition, gyrotron performance can be diagnosed from calorimetry of the internal relief loads, cavity and launcher structures. In the DIII-D gyrotron complex, an automatic system which measures the cooling water flow and temperature increase in nine circuits, is monitored on each gyrotron pulse for the six installed tubes. The circuits are the collector, cavity, body, launcher and internal loads in the gyrotrons, the matching optics units (MOU), fast mode conversion and backup dummy loads outside the gyrotrons and the rf window separating the gyrotron interiors from the outside world.

In principle, the gyrotron output power can be inferred from just the window cooling calorimetry plus knowledge of the microwave absorption at the operating frequency of $110 \mathrm{GHz}$. Three of the DIII-D gyrotrons use boron nitride output windows, which absorb about $4 \%$ of the transmitted power and are heated to central temperatures up to a limit of about $1000^{\circ} \mathrm{C}$. Calorimetry on the cooling circuits for these windows is reasonably accurate, since $30 \mathrm{~kW}$ is dissipated in the window cooling circuit for pulse lengths up to $2.0 \mathrm{~s}$. The development of artificially grown diamond windows, with typical absorption of about $0.2 \%$, has permitted the generation of Gaussian rf beams, however the very low absorption, only about 1-2 kW, has made it difficult to obtain accurate calorimetry data.

An additional complication arises, specifically in the DIII-D case, due to the configuration of the cooling system.
All gyrotron cooling water circulates from a bank of pumps connected in parallel to the gyrotron manifolds, which are also connected in parallel. A typical gyrotron operates at $30 \%$ electrical efficiency to generate about $800 \mathrm{~kW}$, meaning that on each gyrotron pulse about $2.6 \mathrm{MW}$ is dissipated in the cooling circuits. On each pulse each gyrotron heats a volume of water, which circulates back to the reservoir and is returned, more or less coherently, to the gyrotron manifolds. Although the reservoir is cooled by a heat exchanger system, the mixing is rather poor. These packets of hot water appear at random times with respect to the gyrotron firing cycle and can have the time dependence of normal cooling loads, making accurate measurements difficult.

In the DIII-D system, water flow is measured using vortex meters to an accuracy of about $5 \%$ and temperatures are measured at the manifolds using platinum resistance temperature devices (RTDs) having an accuracy of about $0.1^{\circ}$. The main compromise in the accuracy of the measurements comes from the fluctuating baseline temperatures of the circulating water.

\section{MEASUREMENTS}

The rf output power generated by a specific gyrotron can be measured directly by directing the rf beam to dummy loads which are cooled by water and monitored calorimetrically. This power can be related to calorimetry of the output window. Then, when the rf beam is directed to the tokamak, the window calorimetry plus measured or estimated transmission line losses, can be used to estimate the injected power. In Fig. 1 the power distribution for the circuits external to the gyrotron is presented. The problem for accuracy of the measurement of the power injected into the tokamak comes from the difficulties noted above of accurately measuring the very low window heat load both for pulses directed to the dummy loads and for pulses directed to the tokamak.

Consider the calorimetry response curve plotted in Fig. 2. For single pulses of sufficient total energy, the heat deposition time is short, several seconds, compared with the cooling collection time, which is at least tens of seconds and, for some circuits, minutes. The deposited power is calculated from

$$
\mathrm{P}_{0}=\left[\mathrm{F}(\mathrm{gpm}) \cdot(0.264)(\mathrm{kW} / \mathrm{gpm} / \mathrm{deg}) \int \Delta \mathrm{Tdt}\right] / \tau_{\mathrm{p}}(\mathrm{s})
$$

where typical peak values of $\Delta \mathrm{T}$ are $1-2^{\circ} \mathrm{C}$. Fluctuations in the baseline temperature can be relatively small and random, as indicated in the figure, presenting a soluble baseline subtraction problem. But, as discussed above, a 10 or 20 s long slug of hot water, perhaps from a fast compact dummy load 


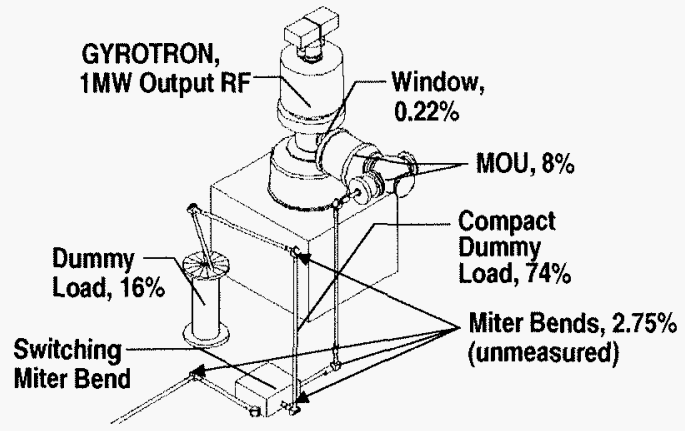

Fig. 1. Distribution of heat loading on components external to the gyrotron as a function of the generated power. The very low loading on the CVD diamond window makes a calibration during dummy load operation and subsequent rf power measurements during plasma operations problematic. Each simple miter bend accounts for about $0.8 \%$ loss due to mode conversion and ohmic heating. Polarizing miters have slightly higher loss, about $1.2 \%$. Heating of the miter bends and interconnecting waveguide is not monitored in the DIII-D calorimetry system.

somewhere in the system, which absorbed three quarters of the gyrotron output power, can easily be physically located between the RTDs of another cooling circuit when a pulse is fired. These rogue warm water pulses, which can represent many times the power absorbed by the window, can render the calorimetry measurement from a low power circuit like the window unusable. In Fig. 3, a series of measurements taken over three consecutive days is summarized in which the generated $\mathrm{rf}$ power was inferred from calorimetry measurements of the diamond window cooling water. The scatter in the data is as high as $\pm 50 \%$ for the shortest pulses for which calorimetry baseline shifts contribute the largest relative errors. Although for the longest pulses, $5.0 \mathrm{~s}$ in duration, most points cluster within about $\pm 10 \%$, there still remain outliers.

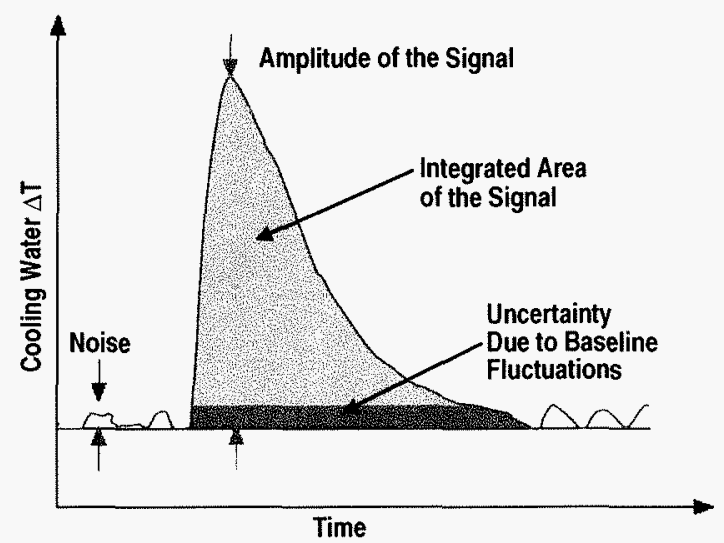

Fig. 2. A generic calorimetry response to an $\mathrm{rf}$ pulse short compared with the energy collection time for the calorimetry circuit. The calorimetry energy collection times for $5 \mathrm{~s} \mathrm{rf}$ pulses can be as long as $200 \mathrm{~s}$ for the backup dummy load or as short as $20 \mathrm{~s}$ for the window and mode conversion dummy loads. After a period of operation, multiple packets of warm water are circulating through the cooling system, causing errors in the measurements.

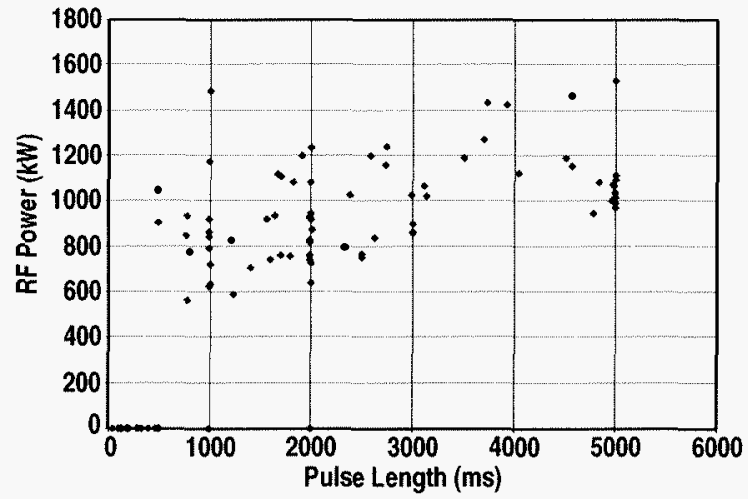

Fig. 3. The generated if power inferred from the window calorimetry response has unacceptably poor accuracy, particularly for shorter if pulses.

Calorimetry of the gyrotron internal cooling circuits can provide larger signals than the window calorimetry, but if these are used, a correspondence between them and the $\mathrm{rf}$ output must be established.

Gains of at least a factor of 6 in calorimetry response can be realized from measurements on other gyrotron cooling circuits than the window, as summarized in Fig. 4. In some cases, such as the rf cavity cooling, the generated $\mathrm{rf}$ is approximately proportional to the heat loading. In the case of the collector cooling circuit, however, although a very large and very rapid calorimetry response is available, the collector loading increases as the rf output decreases at constant input power and it must be verified that the gyrotron is operating at a known rf efficiency.

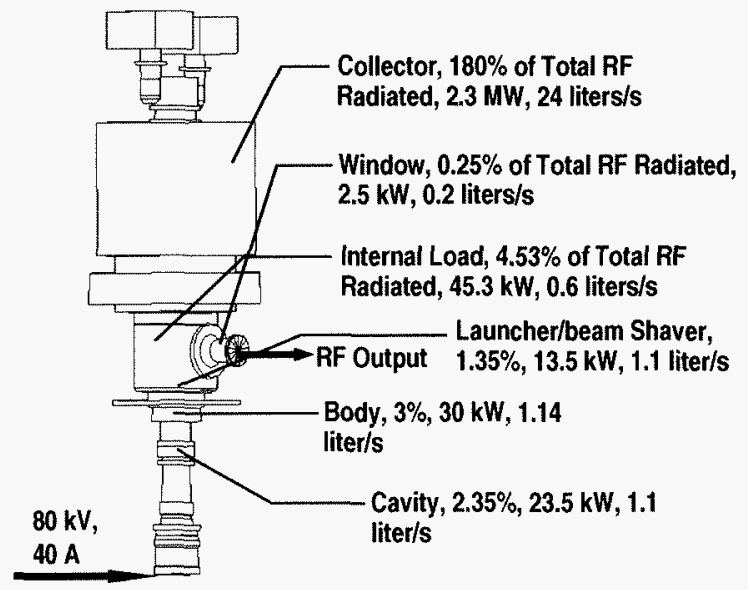

Fig. 4. Although heat loading on internal components of the gyrotrons could in principle be used to measure the generated rf power, these loadings cannot be relied upon to provide a response which is proportional to the generated power.

\section{WAVEGUIDE POWER MONITOR}

In order to obviate these difficulties, a new power monitor has been developed. The device is installed in the waveguide at a location where the transmitted power is required. In the case of the DIII-D installation, this is in the last straight waveguide before the $\mathrm{rf}$ is injected into the tokamak. The 
device introduces a small gap in the circular waveguide carrying the fundamental $\mathrm{HE}_{1,1}$ mode. About $400 \mathrm{~W}$ of $\mathrm{rf}$ power leaks out through this gap for $800 \mathrm{~kW}$ transmitted rf. This rf power heats a $\mathrm{TiO}_{2}$ absorber on the inner wall of a cylinder exposed to the leakage. The temperature of the cylinder in this area is compared to that of the end flanges to estimate the power. Operation depends on the rapid heat flux through the stainless steel wall of the cylinder compared with the longitudinal heat flux to the flanges. The device is not actively cooled, eliminating the fluctuating baseline problem associated with calorimetry and provides a good measurement using only the few degree temperature increase during the initial portion of the thermal response. The device and response to transmitted of is shown in Fig. 5.

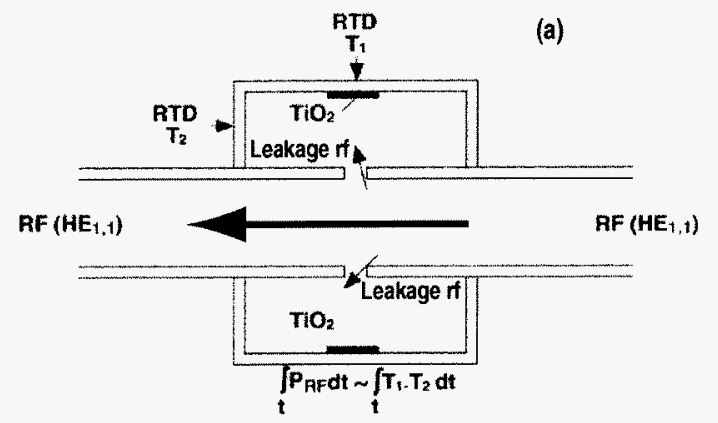

\section{CONCLUSION}

Calorimetric measurements of the rf power generated by gyrotrons have become more difficult with the development of output windows having extremely low microwave absorption. The problem is exacerbated in the DIII-D system by the poor control of the temperature of the cooling water and the location of sensors some distance from the corresponding heat loads. A power monitor based on leaky waveguide has been developed and is in test.

\section{ACKNOWLEDGMENT}

Work supported by the U.S. Department of Energy under Contracts DE-AC03-99ER54463 and DE-AC05-00OR22275.

Fig. 5. A vacuum compatible waveguide power monitor has been developed (a), which promises to provide a direct measurement of the rf power transmitted through it. The traces (b) shown are the individual RTD responses to a $1 \mathrm{~s}$ rf pulse, from which the power measurement will be derived. The response to peak temperature difference is rapid and the device is not actively cooled, eliminating problems with baseline fluctuations. The in-line calorimeter labeled \#2 and \#3 are the response of two RTOs on a unit close to the gyrotron. The peak in the response may be adequate for the measurement. 